\title{
Perceived Risk in Tuanzhu Group Buying and Traditional Online Buying in Taiwan
}

\author{
Ying-Yu Chen ${ }^{1}$, Yi-Shiang Duan ${ }^{2}$, Jia-Jen $\mathrm{Ni}^{3}$, Jin-Long Liang ${ }^{4}$ \\ ${ }^{1}$ Department of Business Administration, Aletheia University, Taiwan \\ ${ }^{2}$ Department of International Business, Kainan University, Taiwan \\ ${ }^{3}$ International Trade Department, Chihlee University of Technology, Taiwan \\ ${ }^{4}$ Department of International Business, Vanung University, Taiwan \\ Correspondence: Ying-Yu Chen, Department of Business Administration, Aletheia University, No.32, Zhenli St., \\ Tamsui Dist., New Taipei City 251, Taiwan (R.O.C.). E-mail: moon1501@gmail.com
}

Received: October 10, 2016

Accepted: October 25, 2016

Online Published: November 8, 2016

doi:10.5539/ibr.v9n12p92

URL: http://dx.doi.org/10.5539/ibr.v9n12p92

\begin{abstract}
Consumers who have adopted tuanzhu group buying (TGB) changed from one-on-one online buying to buying led by a tuanzhu (ie. group leader). The tuanzhu integrates the demands and funds of multiple consumers and is responsible negotiating with the seller to achieve better transaction results as well as to acquire more information about the product to reduce various kinds of risk. However, the TGB mechanism is marred by delays and uncertainties, which can trigger potential customer risks. We recruited as participants 193 college students from four business schools. All students participated in the research voluntarily. The respondents were randomly assigned to the traditional online buying and TGB groups. Of the 193 surveys distributed, 146 were returned. Results of this study show that consumers' perceived risk is higher with TGB than with online buying. As a result, TGB is much more complicated than traditional online buying, and thus consumers' perceived risk is higher with TGB than with traditional online buying.
\end{abstract}

Keywords: e-commerce, group buying, internet marketing, online buying, perceived risk, tuanzhu

\section{Introduction}

Kalakota and Whinston (2001) noted that e-commerce is generally defined as a modernized business model that integrates shopping for commercial products with activities such as sales and the services provided through computer networks. E-commerce has been growing rapidly in recent years, which has led many researchers to try to find criteria for success in applying this new business mode (Matsuo, Ito, \& Shintani, 2005)

E-commerce can be divided into five categories: business to business (B2B), consumer to consumer (C2C), business to consumer (B2C), B2P (business-to-public) and B2G (business-to-government). B2C is a kind of traditional online buying in which businesses transact with consumers through the Internet. The seller presents on its web page information about the product's appearance and features, as well as its price (usually both the list price and discounted price) and the methods of payment and delivery. Consumers then browse the web page and decide whether they want to buy the product. Traditional online buying use a fixed-price mechanism and the seller and the consumer maintain a simple one-on-one relationship in which the consumer is not connected with any other consumers. Well-known traditional online buying websites include Amazon (www.amazon.com) and Wal-mart (www.walmart.com) in the U. S. and books.com.tw and 7-11's Internet channel 7net (www.7net.com.tw) in Taiwan.

Although $\mathrm{B} 2 \mathrm{C}$ is still very important in e-commerce, $\mathrm{C} 2 \mathrm{C}$ is on the rise. The main reason is that $\mathrm{C} 2 \mathrm{C}$ makes it easier for consumers to create online platforms to run their own businesses, although they can also use existing business platforms such as eBay or Yahoo's auction system. This has led many researchers to investigate online auction behavior (e.g., Ho, 2008; Livingston, 2010) or online group buying behavior.

The purpose of online group buying is to provide mass quantities of a product at a low price to aggregate population of buyers (Anand \& Aron, 2003). This large number of consumers allows businesses that use group buying to avoid the cost of middlemen and save individual shipping charges by making large-volume shipments. 
The savings are passed on to consumers in lower prices. The emergence of online group buying has meant that the Internet provide an electronic virtual environment that supports huge advances in consumer network community functions. In a free and virtual network space, Internet users share their experiences or compare prices, making product information more transparent. Therefore, a group of consumers with identical shopping demands - a thematic consumer community - is formed. The group can then make purchases through a bulletin board system (BBS) or a platform established by the seller.

In China and Taiwan, online group buying is referred to as tuangou. This type of e-commerce is especially popular in East Asia. According to Kauffman, Lai, and Ho (2010, p250):

For the Taiwan region, the well-known group-buying website iHergo was opened in March 2007. It was visited by 20,000 people and among them, 2,000 registered as members in the first month. During the first five weeks, 4,000 successful transactions were completed... Another reputable group-buying platform PTT was launched in March 2008. At PTT, there were more than 450 recruiting posts available every day (Kauffman, Lai, \& Ho, 2010).

However, not every buying group shares identical operations. Online group buying exists mainly in three forms. (1) Group buying coupons: If a certain number of people jointly make an offer that meets or exceeds the predetermined minimum quantity, the deal becomes available to all. After paying, the consumers download their coupons through email or text messages. Finally, they exchange their coupons for the product at the company. Group-buying coupons are especially popular in Europe and the U.S. A good example is Groupon (www.groupon.com). Such group buying websites usually adopt a "deal-of-the-day" transaction model (Liu \& Sutanto, 2012). (2) Online convergence, offline purchase. In this model, the website distributes group-buying certificates to users, who then directly meet at the store for the purchase, where they can request group-buying discounts from the company for the products they prefer. They reach an agreement with the company and then make their purchases. This form of online group buying is common in China; examples are Liba.com (www.liba.com) and TeamBuy (www.teambuy.com.cn). (3) Tuanzhu group-buying (TGB): In this model, the website offers consumers an exchange platform which they use to form their own group-buying teams. The leader of the team, called the tuanzhu, is responsible for team members to communicate with the seller. The tuanzhu can be a seller, a consumer, or a third party to the transaction (Kauffman, Lai, \& Lin, 2010). Most group buying sites in Taiwan and Hong Kong adopt this type of business model, including the well-known Taiwanese sites BuyTogether (www.ptt.cc) and iHergo (www.ihergo.com).

Under the tuanzhu model, the group-buying leader is responsible for the group-buying team, which is consisted of users from BBS or internet users. The model is actually a combination of $\mathrm{B} 2 \mathrm{C}$ and $\mathrm{C} 2 \mathrm{C}$. The buying process is detailed in Figure 1. First, the tuanzhu searches for an appropriate product. After confirming the discount requirement, the tunazhu posts a message on the site with "group buying" as the subject line. The tuanzhu then waits to see if he or she can gather enough people who are willing to meet the minimum required quantity. If this endeavor fails, the group buying is cancelled. If it succeeds, the tuanzhu negotiates the delivery and payment methods with the team members. After confirming payment from all the team members, the tuanzhu implements the agreement and delivers the products. The team members browse messages related to the group buying. If they decide to participate, they leave a message informing the tuanzhu of their contact information. They then wait for the tuanzhu's confirmation as to whether the group buying will proceed as well as the delivery and payment methods. If the group buying is successful, users pay the tuanzhu and receive their products.

Members
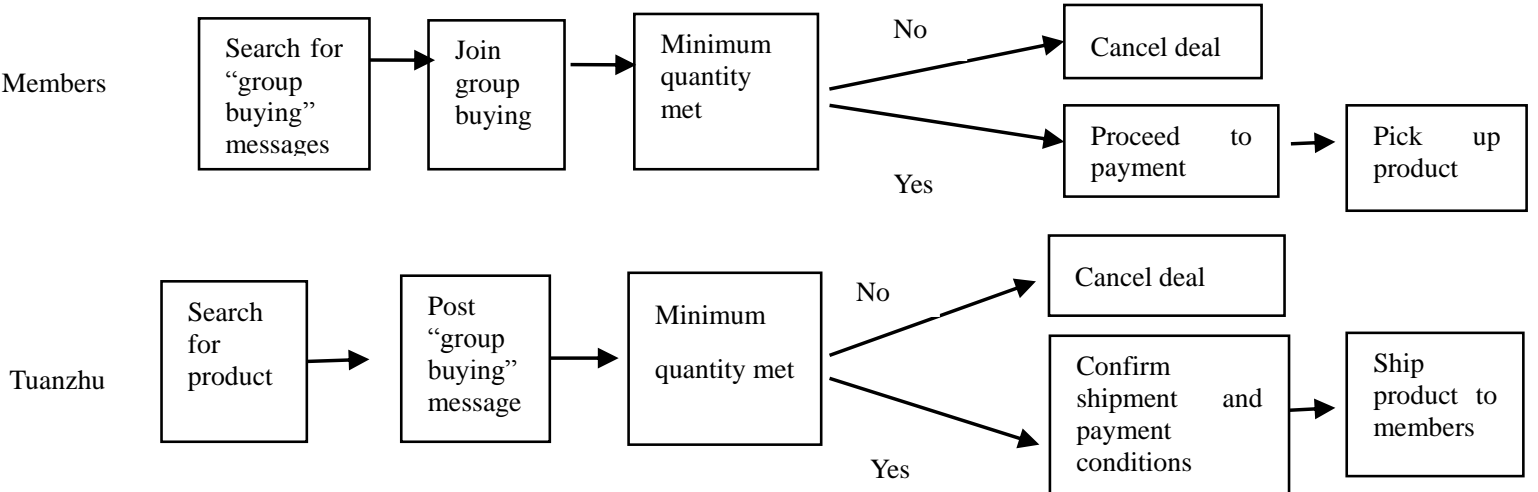

Cancel deal

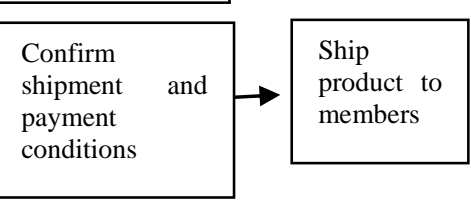

Figure 1. The group buying process for the tuanzhu and team members 


\section{Material Studied}

We next provide some additional information on online buying, perceived risk, and TGB.

\subsection{Online Group Buying}

Yamamoto and Sycara (2001) stated that consumers engage a unified information system through online group buying, which enhances its benefit. Online group buying allows more consumers to participate in the process, and the competitive interactions among consumers, and the collective power that entails, lead to mutual benefits. Also, online group buying allows users to exchange messages to lower transaction uncertainty and risk.

Online group buying differs from traditional online buying group in four ways: (1) Online group buying provides volume discounts -- the more that is bought, the larger the discount. However, the discount is available only if the minimum quantity set by the seller is met (Anand \& Aron, 2003). (2) Online group shopping can effectively reflect the changing relationship between the purchase quantity and price (Matsuo et al., 2005). (3) In contrast to traditional sales, consumers participating in online group buying can decide on the price they are willing to pay. This mechanism is similar to open auctions (Chen, Kauffman, Liu, \& Song, 2010).

Lai and Zhuang (2004) asserted that consumers generally have three types of incentive to participate in online buying: sequence-based, time-based, and quantity-based. In Taiwan, TGB is generally geared toward quantity-based incentives. The seller sets a minimum quantity and then offers a discount once that minimum is met. Whereas members participating in group buying receive the products at a cheaper price, tuanzhus get not only the same price but also a handling fee from the team members plus a premium from the seller. Moreover, tuanzhus use their human networks to attract more people. Therefore, the tuanzhus benefit more from the process than do the team members. The sellers can benefit by capturing the attention of more consumers through the tuanzhu's human network, thereby boosting their product's exposure and achieving the benefit of word-of-mouth marketing. More purchases from consumers mean added revenue for the sellers (Anand \& Aron, 2003). Because tuanzhus personally receive and distribute the product shipments, the sellers lower their administrative and channel costs. Accordingly, both sellers and consumers benefit from online group buying, a win-win situation ( $\mathrm{Li}$, Chawla, Rajan, \& Sycara, 2004; Rha \& Widdows, 2002).

\subsection{Perceived Risk}

The concept of perceived risk was first proposed by Bauer (1967), who defined it as the severity of uncertainty and related outcomes. Stone and Grønhaug (1993) further noted that because consumers expect products to perform well and generate satisfaction, perceived risk in the consumer behavior context should emphasize potential negative outcomes (in contrast to the emphasis on the possibility of both positive and negative outcomes that one finds in other contexts). Therefore, Stone and Grønhaug (1993) defined perceived risk as consumers' subjective expectation of loss.

The literature indicates that perceived risk is a multidimensional construct (e.g., Grewal, Gotlieb, \& Marmorstein, 1994; Hanafizadeh \& Khedmatgozar, 2012; Horton, 1976; Jacoby \& Kaplan, 1972). This includes (1) performance risk - the loss resulting from a product performing below expectation; (2) financial risk - net loss of customers' money; (3) time risk - time wasted due to an inferior buying decision; (4) psychological risk - a negative effect on consumers' peace of mind or self-concept caused by making a poor choice to purchase the product choice or the product performing badly ; (5) social risk - harm to consumers' social status caused by purchasing the product; and (6) physical risk - bodily harm caused by using the product. Although the studies of Jacoby and Kaplan (1972) and Kaplan, Szybillo and Jacoby (1974) showed that for most product categories performance risk has the strongest predictive power on overall risk, many other researchers have found that the predictive power of perceived risk depends on the chosen product's context. For example, in a study of the predictive power of different kinds of risk on the overall perceived risk in purchasing counterfeit sunglasses, Veloutsou and Bian (2008) showed that only psychological risk significantly predicted overall perceived risk in two contexts (UK and China). On the other hand, Stone and Grønhaug (1993) found that financial and psychological risks were the significant predictors of overall perceived risk in purchasing a personal computer. Kunze and Mai (2007) found that when consumers used an online music service, performance risk and time risk were the best predictors of overall perceived risk, whereas social risk and psychological risk were the poorest predictors.

In the e-commerce literature, one finds that many studies have focused on differences in consumers' perceived risk in online versus non-online transaction modes. For example, Tan (1999) and Donthu and Garcia (1999) asserted that because online buyers are unable to actually confirm product quality during the shopping process, they have a higher level of perceived risk. Harridge-March (2006) pointed out that the risk in online transactions 
stems from factors such as opportunism exhibited by anonymous trading partners, sellers obtaining personal information, and the inability of the buyer to actually inspect the product. Featherman, Valacich, and Wells (2006) found that when physical service procedures were digitalized to become online electronic services, the perceived artificiality increased the perceived risk of these electronic services. Cunningham, Gerlach, Harper, and Young (2005) and Cunningham, Gerlach, and Harper (2005) compared online flight booking with traditional flight booking, and electronic banking service with traditional banking service. They found that in both cases online users perceived a higher risk than traditional users at each stage of the buying process. In an analysis of retailers who integrate with both the Internet and physical stores to form a "multichannel," Korgaonkar and Karson (2007) found that consumers' channel preferences were easily affected by perceived risk. The consumers had the highest preference for prestige-oriented multichannel retailers (selling high-priced accessories, for example), followed by value-oriented multichannel retailers (offering volume discounts, for example), and, last, exclusively online retailers. Although the above researchers compared the perceived risk of online transactions with that of non-online or hybrid transactions, few studies have examined the effect of different types of online buying modes on consumers' perceived risk. Therefore, the purpose of this study was to extend our knowledge in this area.

\subsection{The Risk in TGB}

Traditional online buying has the characteristics of $\mathrm{B} 2 \mathrm{C}$, a fixed price mechanism, and no connections among consumers. Along with the widespread applications of the Internet, transaction methods have become increasingly diversified. TGB is one of the emerging online transaction modes. In contrast to traditional online buying, TGB is led by a leader who ascertains market trend and receives funds from multiple consumers. The leader is responsible for negotiating prices with sellers to get lower price. In addition to benefiting the tuanzhu, the team members, and the seller, TGB allows the tuanzhu and the team members to obtain discounts while lowering the seller's risk. Kauffman and Wang (2001) documented that consumers are unable to make rational purchase decisions that optimize value because of information distortion and their inability to detect related changes in all products in the market. However, in TGB, the tuanzhu introduces and recommends the product to the consumer. In other words, prior to making a purchase, consumers receive thorough information about the product, such as its specifications, quality, and comparisons with other products available in the market. On the other hand, members that participate in TGB share their experiences and related information. This helps lower their perceived purchase risk.

However, for the TGB team to be successful, a minimum product quantities have to be recruited. Therefore, neither the buyers nor the seller can immediately guarantee a successful transaction. In other words, TGB has the disadvantages of "delay" and "uncertainty." Delay lowers the transaction's utility and increases the uncertainty connected with risk-aversion. These problems further decrease the ultimate value of the transaction (Anand \& Aron, 2003). TGB, owing to its convergent buying characteristic, allows consumers to receive more information about the product and thus decrease their product risk. However, due to the unique nature of its transactions, TGB may enhance consumers' risk. This is why existing theories are unable to explain consumers' perceived risk in online group buying. Accordingly, the first research question addressed in the current study was whether consumers participating in TGB or those participating in traditional online buying perceive the greater risk.

As TGB is an emerging phenomenon, the literature has not yet addressed the difference in overall perceived risk between traditional online buying and TGB. The impact caused by the risk dimensions of both transaction groups has also not been examined. As mentioned above, perceived risks include several dimensions (psychological risk, time risk). As the purpose of our study was to explore the perceived risk of two online transaction methods, consumers' psychological and social risks were excluded. The reason is that consumers who are familiar with computers and accustomed to conducting online transactions are likely to accept new (for them) online transaction mechanisms. Therefore, they would not perceive a different online transaction mechanism as harmful to their self-image. In contrast, consumers who insist on making their transactions in physical shops and generally resist online transactions are likely to be especially resistant to a new (for them) type of online transaction, because they would perceive it as harmful to their self-image. Similar considerations apply to social risk. If individuals' computer usage and familiarity with online buying are minimal, their peer group or social group may influence them to accept or reject online transaction modes.

The current study focused on performance risk, financial risk, time risk, and privacy risk. Accordingly, the second research question we addressed was whether consumers who adopt TGB differ from those who adopt traditional online buying in terms of performance risk, financial risk, time risk, and privacy risk.

Answers to the above questions cannot be found in the existing literature. This study addressed two specific 
research objectives. First, we compared consumers who adopt TGB and those who adopt traditional online buying to determine which group perceives the greater overall risk. Second, we compared the two groups on the specific perceived risk dimensions indicated above.

Different objects may affect consumers' perceived risk (e.g., Korgaonkar \& Karson, 2007). In traditional online buying, consumers often deal with well-known shopping sites (e.g., Amazon), whereas consumers who adopt TGB frequently run into a tuanzhu and members of that tuanzhu's group whom they are unfamiliar with. Applying information economics to the area of brand management, Rao, Qu, and Ruekert (1999) proposed that sellers use "signals" to reliably transmit unobservable product information to buyers. These signals may include items such as certificates, advertising expenses, and brand. Although in the TGB context tuanzhus and their members can provide information on different products, it is difficult for the information to become a signal of reduced perceived risk. The reason is that consumers often do not know the members and lack understanding of the tuanzhu's background information. In addition, the average group-buying website does not offer a rating system of the product's characteristics. As a result, the information on group-buying websites is often unconvincing. On the other hand, a certain level of uncertainty exists in the TGB procedure. For example, consumers are uncertain as to whether members are likely to join the TGB, and if so how many and when, as well as whether their expectation of a lower price would be met. Therefore, we posited the following hypothesis:

Hypothesis 1: TGB consumers perceive greater risk than traditional online buying consumers.

Performance risk denotes errors and failures to operate normally during traditional online buying and TGB. The traditional online buying process is relatively simple. Consumers need only decide which product they wish to buy. They then purchase the product online and make the payment transfer. The buyer only has to contact a well-known online buying website. With TGB, although the transactions can be conducted on well-known websites/portals, the process requires the tuanzhu to play the role of communicator between a large number of TGB members and the seller. In addition, the tuanzhu must handle many other duties, including payments and deliveries. Unfortunately, the professionalism of tuanzhus varies and their level of information transparency trails that of well-known online buying sites. In addition, they have to handle complicated transactions as well as product returns/exchanges. On the other hand, with traditional online buying, returns and exchanges are generally made directly between buyers and sellers. As a result, consumers are more concerned about running into problems with TGB than with traditional online buying. Therefore, we put forth the following hypothesis:

Hypothesis 2: TGB consumers perceive higher performance risk than traditional online buying consumers.

Financial risk is related to the money spent in the original purchase and subsequent maintenance costs. In addition, it can include financial losses arising from fraud (Featherman \& Pavlou, 2003). In contrast to the case of well-known shopping sites, TGB members often do not know the tuanzhu. Thus, they may be concerned about financial losses that might occur if they pay for but do not receive the product. Therefore, we posited the following hypothesis:

Hypothesis 3: TGB consumers perceive higher financial risk than traditional online buying consumers.

In traditional online buying characterized by fixed-price sales, consumers generally make purchases and payments immediately. In TGB, tuanzhus must wait for members to join to enhance their price negotiation ability. If the minimum quantity is not met, consumers' expectation of drop in price will be nullified. In this case, consumers must continue to wait for the tuanzhu or some other tuanzhu to launch another purchase. Even if the purchase is successful and the seller completes the transaction, consumers have to wait for the tuanzhu to determine the delivery time and handle the delivery. As a result, the consumers are likely to experience different types of delays during the buying process. Therefore, we put forth the following hypothesis:

Hypothesis 4: TGB consumers perceive higher time risk than traditional online buying consumers.

Lee (2002) indicated that protection of personal information has the highest relative importance in online purchasing. With traditional online buying, consumers' personal information related to making a transaction is processed and saved by well-known shopping sites. With TGB, consumers frequently have to deliver personal information to the tuanzhu, whom they are unfamiliar with. In addition to payment time, name, address, and phone number, some consumers are even required to give partial or complete bank account numbers. Although consumers are reluctant to reveal confidential information to an unknown third party (Mascha, Miller, \& Janvrin, 2011), they still face the threat of opportunism from the tuanzhu. For example, the tuanzhu may sell member's information to email advertisers or other potential sellers of related products. Also, the tuanzhu may disclose members' information accidentally. For example, if the tuanzhu's computer is infected by a Trojan virus, members' personal information could be stolen or even leaked to fraudulent organizations. Therefore, consumers 
participating in TGB would be expected to have more concerns that their personal information will be abused than would traditional online buying consumers.

Hypothesis 5: TGB consumers perceive higher privacy risk than traditional online buying consumers.

\section{Method}

\subsection{Pre-test}

To ensure that the experimental situation conformed to the expectations of the participants, we distributed a pre-test questionnaire to 40 college students from business school to measure their interest in buying various products online. The results showed that cake was a suitable product for the formal experiment. This product also conforms to Taiwan's present circumstances in that food is one of the most popular products categories in Taiwan for online purchase.

\subsection{Participants}

Because college students are familiar with online buying, past studies mostly used college students as the research participants (e.g., Lee \& Tan, 2003), and then we students to join invented in the study. We recruited as participants 193 college students from four business schools. All students participated in the research voluntarily. Prior to the start of the research, respondents were clearly informed about the anonymity of the survey and that it was purely for academic purposes.

\subsection{Materials}

The survey questionnaire begins with questions about participants' sex, age, Internet use habits, and demographics. Past studies differed in the dimensions, definitions, and measurement of perceived risk. For example, in examining online buying, researchers usually have included the privacy risk dimension into perceived risk (e.g., Ueltschy, Krampf, \& Yannopoulos, 2004; Zhao, Hanmer-Lloyd, Ward, \& Goode, 2008) and operationalization of the risk dimensions was associated with purchasing specific products (e.g., Stone \& Grønhaug, 1993). However, our emphasis was not on specific products but on online transaction modes. The latter theme is more compatible with that of Featherman and Pavlou (2003), who studied the perceived risk of electronic services. Therefore, we followed Featherman and Pavlou (2003) in specifying the risk dimensions, and defining and measuring perceived risk. This led us to specify overall risk, performance risk, financial risk, time risk, and privacy risk as our dimensions. Modifications were then made to the items in Featherman and Pavlou's (2003) questionnaire according to mode. For example, one item measuring financial risk in traditional online buying is: "Buying a cake online subjects my bank account to potential fraud." The corresponding item for TGB is: "Group buying a cake online subjects my bank account to potential fraud." One item on privacy risk in traditional online buying is: "Buying a cake online would lead to a loss of privacy for me because my personal information would be used without my knowledge." The corresponding item for TGB is: "Group buying a cake online would lead to a loss of privacy for me because my personal information would be used without my knowledge."

\subsection{Design}

The independent variable in our study was online buying mode ( traditional online buying vs. TGB) and the dependent variable was perceived risk. Ttraditional online buying was defined as buying through online websites and TGB was defined as group buying on group-buying websites initiated by a tuanzhu. The literature shows that product category and features (e.g., Ueltschy et al., 2004), channel characteristics and product reputation (e.g., Kauffman, Lai, \& Ho, 2010), online buying experiences (e.g., Soopramanien, Fildes, \& Robertson, 2007), and payment method affect perceived risk. Therefore, the above variables were kept constant across modes. For both modes, we used website reputation purchasing experience and payment term as control variables The objective was to purify effect o perceived risks on transaction modes.

The respondents were randomly assigned to the traditional online buying and TGB groups. There is no missing data.

\subsection{Procedure}

The experiment was conducted in a laboratory equipped with projector equipment. After explaining the buying situations with Powerpoint, respondents were given ample time to complete the survey.

\section{Results}

\subsection{Descriptive Statistical Analyses}

Of the 193 surveys distributed, 146 were returned, 94 from female respondents and 52 from male respondents. 
Most of these participants were under 20 years of age (58.2\%), $45.2 \%$ were full-time students, $36.3 \%$ had part-time jobs, $18.5 \%$ had full-time jobs, and $62.3 \%$ had online group-buying experience (see Table 1 ). As shown in Table 2, the means for the individual risk dimensions ranged from 2.99 to 3.54, and Cronbach's $\alpha$ of risk dimensions ranged from 0.78 to 0.89 , exceeding the threshold of 0.7 suggested by Nunnally (1978).

Table 1. Descriptive Statistics for the Demographic Variables

\begin{tabular}{llll}
\hline Variable & Range & Frequency & Percentage \\
\hline Sex & Male & 52 & 35.6 \\
& Female & 94 & 64.4 \\
Age & Under 21 & & \\
& $21-30$ & 55 & 58.2 \\
& Over 30 & 4 & 39 \\
Employment & Full-time job & & 2.8 \\
& Part-time job & 27 & 18.5 \\
& Full-time student/Not working & 53 & 36.3 \\
\hline
\end{tabular}

Table 2. Descriptive statistics for the perceived risk dimensions

\begin{tabular}{llll}
\hline Dimension & Mean & SD & Cronbach's $\alpha$ \\
\hline Overall risk & 3.10 & 0.80 & 0.89 \\
Performance risk & 3.37 & 0.66 & 0.78 \\
Financial risk & 3.09 & 0.70 & 0.81 \\
Time risk & 2.99 & 0.81 & 0.85 \\
Privacy risk & 3.54 & 0.78 & 0.81 \\
\hline
\end{tabular}

\subsection{Independent Sample T-tests}

Independent sample $t$-tests were performed comparing the two buying mode groups (traditional online buying and TGB) on the different dimensions of perceived risk. As illustrated in Table 3, the mean differences between the two groups on financial, performance, privacy, time, and overall risk all reached significance $(p<0.05)$ with the TGB mean being higher than the traditional online buying mean in all cases. All five hypotheses were thus supported.

Table 3. Independent $t$-tests comparing traditional online buying and TGB

\begin{tabular}{llll}
\hline Dimension & Mean & TGB Mean & t value \\
\hline Overall risk & 2.89 & 3.31 & $3.312^{* * *}$ \\
Performance risk & 3.17 & 3.56 & $3.783^{* * *}$ \\
Financial risk & 2.92 & 3.26 & $2.750^{* *}$ \\
Time risk & 2.83 & 3.14 & $2.421^{*}$ \\
Privacy risk & 3.40 & 3.68 & $2.164 *$ \\
\hline
\end{tabular}

$* p<0.05 ; * * p<0.01 ; * * * p<0.001$

\section{Discussion}

The online transaction and perceived risk literature generally compares online transactions to purchases at physical stores (e.g., Cunningham, Gerlach, Harper, \& Young, 2005; Huang, Schrank, \& Dubinsky, 2004). This study extends the related data on perceived risk to comparisons of two online transaction modes (traditional online buying vs. tuanzhu online group buying).

The existing literature rarely addresses the perceived risk of online group buying. For example, Kauffman, Lai, and Lin (2010) analyzed the effect of textual comments and existing bids on perceived financial risk and psychological risk. There are two major differences between the present study and that of theirs. First, their study focused on whether a consumer's decision to bid or not bid on a product was based on the textual comments of a specific tuanzhu or existing bids of those who had already decided to use group buying. Our study, however, emphasized the possibility that differences in customers' perceptions of the risks in traditional online buying vs. TGB. Second, their study focused mainly on financial risk and psychological risk, whereas our study discussed two other risk dimensions, privacy risk and time risk, that are very important in online transactions.

Our empirical findings support the hypothesis that overall perceived risk is higher in TGB than in traditional online buying. In other words, the uncertainties arising from TGB, such as consumers' unfamiliarity with tuanzhu/team members and whether the group buying would be successful, evokes a higher level of perceived risk.

The performance risk of TGB was perceived as higher than that of traditional on line buying, supporting Hypothesis 1. Because TGB involves at least three parties (seller, tuanzhu, and buyers) and thus is more 
complicated that traditional on line buying, consumers may be concerned that the group buying process in TGB will be unsuccessful or run into problems. Results also showed that the TGB group perceived higher financial risk than the traditional on line buying group, presumably because they were concerned about financial losses arising from being cheated by the tuanzhu, with whom they were unfamiliar. As for time risk, Anand and Aron (2003) stressed that delay is an important characteristic of group buying. The findings of our study support this view. The perceived time risk for the TGB group was significantly higher than that for the traditional online buying group. The operative delays likely include the time consumers waste waiting for members to join, looking for other group-buying opportunities if the group fails to meet the minimum quantity, and having to come to terms with the tuanzhu at delivery time. Lastly, consumers adopting TGB must submit their personal information to the unfamiliar tuanzhu. Concern that their personal information would be leaked explains why the TGB group scored significantly higher than the traditional on line buying group on perceived privacy risk.

Even though, as we have shown, Taiwanese consumers' perceive greater risk if they adopt TGB than if they adopt traditional online buying, TGB has rapidly developed in recent years to become an especially popular online buying mode. This can be attributed to the cultural characteristics proposed by Hofstede, Hofstede, and Minkov (2010). Their data show that residents of Taiwan have higher risk-aversion than residents of mainland China and Hong Kong. In other words, Taiwanese consumers are very inclined to use clear legal, system, guidelines, and protection to lower risk and uncertainty. Even though these mechanisms are not established parts of TGB systems, consumers still find TGB appealing. Our study suggests that the major reason for the popularity of TGB is related to Taiwan's inclination toward collectivism, that is, Taiwanese consumers seek interactions with others during the buying process. The purpose of TGB is to gather consumers together who are interested in the same product. During the buying process, participants share detailed product information, usage experiences, and even tidbits about what life is like on the group-buying website. Therefore, even though consumers adopting TGB perceive greater risk than consumers using traditional online buying, they prefer TGB because they are driven by collectivism. In addition to enjoying the discounts and fun of collective shopping, members also develop social networks.

Although group buying is booming in all of East Asia, the cultural characteristics of China, Hong Kong, and Taiwan are different. According to Hofstede et al., (2010), Taiwan has the highest risk-aversion to uncertainty, followed by China and then Hong Kong. Taiwan also has the highest inclination toward collectivism, followed in this case by Hong Kong and then China. In China, the most popular form of group buying at present is "online convergence, offline buying." In this mode, consumers converge in mass numbers and buy products online, but they must bring a certificate to the seller to claim their product. Despite the large number of participants, communicating through messages, which is popular in Taiwan, is not common in China. This could perhaps be explained by the weaker inclination toward collectivism in China. In addition to converging online to chat, TGB members in Taiwan converge at a certain location to claim their products. Because the tuanzhu delivers the products only at a certain time, the consumers must converge at this same time. While they are waiting, they can chat, exchange experiences, examine the products, inform others in the group about their next purchase, and share their experiences with other products. This group-buying mode is very different than what is practiced in China. That means in Oriental societies favoring collectivism, cultural differences still create different preferred online group-buying modes.

\subsection{Practical Implications}

Because the TGB process involves not only a seller and consumers but also a negotiation relationship among buyers, practitioners of e-commerce should pay special attention to our key finding that consumers' perceived risk is higher with TGB than with traditional on line buying. If these practitioners could alleviate consumers' doubts and risk concerns, they could perhaps facilitate the further development of TGB.

First, because TGB is likely to be its members' first experience with group buying, it is important to establish a comprehensive rating system on the group buying platform to reduce mutual distrust between the tuanzhu and the members. In addition to providing general rating mechanisms, the platform should allow customers to give their overall rating of tuanzhu after each transaction. It should provide detail information such as the tuanzhu's success rate, and the average time needed to successfully form a group, and deliver goods. These features would allow previous buying records to be truly reflected and help remove members' risk concerns prior to joining the TGB team. The group-buying platform can also include instantaneous chat software to enhance interaction among sellers, tuanzhus, and members, thereby reducing the likelihood of conflicts and misunderstanding arising from communication errors, lowering the risk of bad purchase decisions, and reinforcing the efficiency of negotiation and discussion. 
Lastly, online group buying's return policy is often trickier than it is with physical or individual online buying. Because in TGB the tuanzhu is the window of communication to the seller, the members should ask the tuanzhu to handle the related matters whenever there is a problem with the product. Alternatively, consumers can directly access the group-buying platform or the seller. Although there is often a grey area, consumers tend to be more concerned about the consequences of participating in group buying than traditional online buying. Therefore, the group-buying platform should communicate clear policies on this issue to ensure that consumers' rights are protected.

\subsection{Limitations and Suggestions for Future Research}

This study used text descriptions supported by Powerpoint to construct hypothetical buying situations. Future researchers should consider obtaining authorization from actual online buying and group-buying websites to present actual web pages in their studies. By doing so, they would enhance the authenticity of the situation and allow respondents to be more involved in the buying.

Also, this study adopted convenience sampling of Taiwanese college students, thus limiting the generalization of the results. First, college students of different nationalities may differ in how much experience they have using the Internet. Second, college and non-college students may differ in how they use the Internet generally and buy online specifically. These differences may lead possible impact on perceived risk and these would be good topics for further study.

At the same time, due to cultural diversity, nations may differ in which group-buying modes are the most popular. These different modes may create differences in perceived risk and its dimensions. Therefore, we suggest that future studies compare perceived risk in different group-buying modes.

This study's comparison of the risk perceived in different online transaction modes involved differences between traditional online buying and TGB. Subsequent studies can extend the research scope to differences in perceived risk with other online transaction modes, such as surrogate buying and Internet auctions.

The sample in this study did not include consumers who had more than two group buying experiences; rather, the sample was limited to persons using group buying websites for the first time. After the members and the tuanzhu have worked together several times, their degree of mutual familiarity is enhanced. Would consumers' perceived risk then gradually diminish? If so, how big is the decrease? After working with the tuanzhu several times, would these consumers have similar or even lower perceived risk than consumers using traditional online buying? These are all possible questions for future studies.

\section{Reference}

Anand, K. S., \& Aron, R. (2003). Group buying on the web: A comparison of price-discovery mechanisms. Management Science, 49(11), 1546-1562. http://dx.doi.org/10.1287/mnsc.49.11.1546.20582

Bauer, R. A. (1967). Consumer behavior as risk taking in D. F. Cox, (Ed). Risk Taking and Information Handling in Consumer Behavior. Harvard University Press, Cambridge, MA, 23-33.

Chen, J., Kauffman, R. J., Liu, Y., \& Song, X. (2010). Segmenting uncertain demand in group-buying auctions. $\begin{array}{llll}\text { Electronic Commerce Research and Applications, } & \text { 9(2), } & \text { 126-147. }\end{array}$ http://dx.doi.org/10.1016/j.elerap.2009.03.001

Cunningham, L. F., Gerlach, J. H., \& Harper, M. D. (2005). Perceived risk and e-banking services: An analysis from the perspective of the consumer. Journal of Financial Services Marketing, 10(2), 165-178. http://dx.doi.org/10.1057/palgrave.fsm.4770183

Cunningham, L. F., Gerlach, J. H., Harper, M. D., \& Young, C. E. (2005). Perceived risk and the consumer buying process: Internet airline reservations. International Journal of Service Industry Management, 16(4), 357-372. http://dx.doi.org/10.1108/09564230510614004

Donthu, N., \& Garcia, A. (1999). The internet shopper. Journal of Advertising Research, 39(3), 52-58.

Featherman, M. S., \& Pavlou, P. A. (2003). Predicting e-services adoption: A perceived risk facets perspective. International Journal of Human-Computer Studies, 59(4), 451-474. http://dx.doi.org/10.1016/S1071-5819(03)00111-3

Featherman, M. S., Valacich, J. S., \& Wells, J. D. (2006). Is that authentic or artificial? Understanding consumer perceptions of risk in e-service encounters. Information Systems Journal, 16(2), 107-134. http://dx.doi.org/10.1111/j.1365-2575.2006.00211.x

Grewal, D., Gotlieb, J., \& Marmorstein, H. (1994). The moderating effects of message framing and source 
credibility on the price-perceived risk relationship. Journal of Consumer Research, 21(1), 145-153. http://dx.doi.org/10.1086/209388

Hanafizadeh, P., \& Khedmatgozar, H. R. (2012). The mediating role of the dimensions of the perceived risk in the effect of customers' awareness on the adoption of Internet banking in Iran. Electronic Commerce Research, 12(2), 151-175. http://dx.doi.org/10.1007/s10660-012-9090-z

Harridge-March, S. (2006). Can the building of trust overcome consumer perceived risk online? Marketing Intelligence and Planning, 24(7), 746-761. http://dx.doi.org/10.1108/02634500610711897

Ho, J. K. (2008). Inter-brand comparison of online auction markets. Electronic Commerce Research, 8(1-2), 103-114. http://dx.doi.org/10.1007/s10660-008-9012-2

Hofstede, G. H., Hofstede, G. J., \& Minkov, M. (2010). Cultures and Organizations: Software for the Mind. New York: McGraw-Hill Professional.

Horton, R. L. (1976). The structure of perceived risk: some further progress. Journal of the Academy of Marketing Science, 4(4), 694-706. http://dx.doi.org/10.1007/BF02729830

Huang, W., Schrank, H., \& Dubinsky, A. (2004). Effect of brand name on consumers' risk perceptions of online shopping. Journal of Consumer Behaviour, 4(1), 40-50. http://dx.doi.org/10.1002/cb.156

Jacoby, J., \& Kaplan, L. B. (1972). The components of perceived risk. In M. Venkatesan (Ed.). Proceedings, 3rd annual conference. Association for Consumer Research, Chicago, IL: Association for Consumer Research, 382-393.

Kalakota, R., \& Whinston, A. B. (1997). Electronic Commerce: A Manager's Guide. Boston: Addison-Wesley.

Kaplan, L. B., Szybillo, G. J., \& Jacoby, J. (1974). Components of perceived risk in product purchase: A cross-validation. Journal of Applied Psychology, 59(3), 287-291. http://dx.doi.org/10.1037/h0036657

Kauffman, R. J., \& Wang, B. (2001). New buyers' arrival under dynamic pricing market microstructure: The case of group-buying discounts on the internet. Journal of Management Information System, 18(2), 157-188. http://dx.doi.org/10.1080/07421222.2001.11045687

Kauffman, R. J., Lai, H., \& Ho, C. T. (2010). Incentive mechanisms, fairness and participation in online group-buying auctions. Electronic Commerce Research and Applications, 9(3), 249-262. http://dx.doi.org/10.1016/j.elerap.2008.11.009

Kauffman, R. J., Lai, H., \& Lin, H. C. (2010). Consumer adoption of group-buying auctions: An experimental study. Information Technology and Management, 11(4), 191-211. http://dx.doi.org/10.1007/s10799-010-0068-z

Korgaonkar, P. A., \& Karson, E. J. (2007). The influence of perceived product risk on consumers ' e-tailing shopping preference. Journal of Business and Psychology, 22(1), 55-64. http://dx.doi.org/10.1007/s10869-007-9044-y

Kunze, O., \& Mai, L. W. (2007). Consumer adoption of online music services: The influence of perceived risks and risk relief strategies. International Journal of Retail and Distribution Management, 35(11), 862-877. http://dx.doi.org/10.1108/09590550710828209

Lai, H., \& Zhuang, Y. T. (2004). Comparing the performance of group-buying models with different incentive mechanisms. In Proceedings of the Third Workshop on e-Business, Association for Information Systems, $1-12$.

Lee, K., \& Tan, S. J. (2003). E-retailing versus physical retailing: A theoretical model and empirical test of consumer choice. Journal of Business Research, 56(11), 877-885. http://dx.doi.org/10.1016/S0148-2963(01)00274-0

Lee, P. M. (2002). Behavioral Model of Online Purchasers in E-Commerce Environment. Electronic Commerce Research, 2(1-2), 75-85. http://dx.doi.org/10.1023/A:1013340118965

Li, C., Chawla, S., Rajan, U., \& Sycara, K. (2004). Mechanism design for coalition formation and cost sharing in group-buying markets. Electronic Commerce Research and Applications, 3(4), 341-354. http://dx.doi.org/10.1016/j.elerap.2004.06.004

Liu, Y., \& Sutanto, J. (2012). Buyers' purchasing time and herd behavior on deal-of-the-day group-buying websites. Electronic Markets, 22(2), 83-93. http://dx.doi.org/10.1007/s12525-012-0085-3

Livingston, J. A. (2010). Functional forms in studies of reputation in online auctions. Electronic Commerce 
Research, 10(2), 167-190. 1 http://dx.doi.org/0.1007/s10660-010-9049-x

Mascha, M. F., Miller, C. L., \& Janvrin, D. (2011). The effect of encryption on Internet purchase intent in multiple vendor and product risk settings. Electronic Commerce Research 11(4), 401-419. http://dx.doi.org/10.1007/s10660-011-9080-6

Matsuo, T., Ito, T., \& Shintani, T. (2005). A volume discount-based allocation mechanism in group buying. In Proceedings of the International Workshop on Data Engineering Issues in E-Commerce, Computer Society, 59-67. http://dx.doi.org/10.1109/DEEC.2005.4

Nunnally, J. (1978). Psychometric theory. New York: McGraw Hill.

Rao, A. R., Qu, L., \& Ruekert, R. W. (1999). Signaling unobservable product quality through a brand ally. Journal of Marketing Research, 36(2), 258-268. http://dx.doi.org/10.2307/3152097

Rha, J. Y., \& Widdows, R. (2002). The internet and the consumer: Countervailing power revisited. Prometheus, 20(2), 107-118. http://dx.doi.org/10.1080/08109020210137493

Soopramanien, D. G. R., Fildes, R., \& Robertson, A. (2007). Consumer decision making, e-commerce and perceived risks. Applied Economics, 39(17), 2159-2166. http://dx.doi.org/10.1080/00036840600749565

Stone, R. N., \& Grønhaug, K. (1993). Perceived risk: further considerations for the marketing discipline. European Journal of Marketing, 27(3), 39-50. http://dx.doi.org/10.1108/03090569310026637

Tan, S. (1999). Strategies for reducing consumers risk aversion in internet shopping. Journal of Consumer Marketing, 16(2), 163-180. http://dx.doi.org/10.1108/07363769910260515

Ueltschy, L. C., Krampf, R. F., \& Yannopoulos, P. (2004). A cross-national study of perceived consumer risk towards online (internet) purchasing. Multinational Business Review, 12(2), 59-82. http://dx.doi.org/10.1108/1525383X200400010

Veloutsou, C., \& Bian, X. (2008). A cross-national examination of consumer perceived risk in the context of non-deceptive counterfeit brands. Journal of Consumer Behaviour, 7(1), 3-20. http://dx.doi.org/10.1002/cb.231

Yamamoto, J., \& Sycara, K. (2001). A stable and efficient buyer coalition formation scheme for e-marketplaces. In Proceedings of the fifth international conference on Autonomous agents. ACM, 576-583. http://dx.doi.org/10.1145/375735.376452

Zhao, A. L., Hanmer-Lloyd, S., Ward, P., \& Goode, M. M. H. (2008). Perceived risk and Chinese consumers' Internet banking services adoption. International Journal of Bank Marketing, 26(7), 505-525. http://dx.doi.org/10.1108/02652320810913864

\section{Copyrights}

Copyright for this article is retained by the author(s), with first publication rights granted to the journal.

This is an open-access article distributed under the terms and conditions of the Creative Commons Attribution license (http://creativecommons.org/licenses/by/4.0/). 